\title{
Pesquisa e ensino do Design: a reconstituição dos figurinos do Ballet Triádico da Bauhaus, no Brasil.
}

\author{
Prof. Dr. Fernando da Silva Ramos \\ FACAMP - Faculdades de Campinas \\ fernandala@gmail.com \\ Prof. Dr. Ernesto Giovanni Boccara \\ UNICAMP - Universidade de Campinas \\ ernestogboccara@terra.com.br
}

Resumo: O mestrado em Moda, Cultura e Arte do Centro Universitário SENAC em São Paulo, desenvolveu um projeto de pesquisa e ensino em nível de graduação e pós-graduação: A reconstituição dos 18 figurinos do Ballet Triádico de Oskar Schlemmer, da escola alemã Bauhaus (1919-1933). O objetivo foi reproduzir fielmente os 18 figurinos, dentro de suas fundamentações conceituais e formais. Por se tratar de um projeto de pesquisa, teve como centro vital de seus objetivos intelectuais e técnicos, a produção de conhecimento, que primeiramente se incorporou entre os mais de 50 participantes (entre pesquisadores, professores e alunos) e em segundo, no legado dos próprios figurinos. Neste artigo faz-se um relato desta experiência, com ênfase aos aspectos relacionados ’a produção dos figurinos, mais especificamente aos trabalhos desenvolvidos na oficina de modelos e protótipos do Design Industrial.

Palavras-chave: Educação/Interdisciplinaridade/Design/Prototipagem

\begin{abstract}
The postgraduate program of fashion, culture and art of Centro Universitário SENAC, has developed a project including research and teaching at undergraduate and postgraduate courses: The reconstitution of the 18 costumes for the Triadic Ballet by Oskar Schlemmer, from the German school Bauhaus (1919-1933). The goal was to faithfully reproduce the 18 costumes within its conceptual and formal foundations. Because it was a research project, had the vital center of its intellectual and technical objectives, in the production of knowledge, which first became part of the more than 50 participants (including researchers, teachers and students ) and second, in the constitution of own costumes. This paper is a report of this experience, with emphasis on aspects related to the costumes production, specifically the work developed at the Industrial Design atelier, on models and prototypes.
\end{abstract}

Keywords: Education/interdisciplinarity/Design/Prototyping 


\section{INTRODUÇÃO: CONCEITOS E DADOS HISTÓRICOS}

O Ballet Triádico da Bauhaus, foi proposto pelo pintor, escultor e dançarino Oskar Schlemmer em sua forma mais completa no ano de 1922. Foi um dos primeiros espetáculos inteiramente abstratos da história. Com ele, Schlemmer demonstra claramente sua estruturação formal em direção à estética racional construtivista.

O artista integrava escultura, pintura, design, dança, teatro oscilando pendularmente na tensão entre o Espaço e o Tempo na construção cênica. A arte da cena se torna aqui uma questão de equilíbrio matemático. O homem em cena é transformado pelo espaço abstrato que sustenta a ação da sua dança. Sua expressão diferencial são os figurinos: é o corpo humano revestido de formas geométricasmatemáticas elementares e dos movimentos no espaço que lhes correspondem.

O Ballet inicia enquanto criação e pesquisa obsessiva de Schlemmer em 1912, bem antes de ser convidado a ser mestre do teatro da Bauhaus. A partir de 1921 foi reunindo alegorias a partir do teatro de marionetes presente na cultura germânica e da commedia del'arte, mantendo forte vínculo com as tradições dos espetáculos populares dos parques de diversões e as apresentações teatrais rocambolescas da cultura alemã. Seria o protótipo para o que viria a ser o Ballet definitivo apresentado em Landestheater de Stuttgart em 1922. Ele o dividiu em três atos. Indo do galanteio ao sério. A primeira parte é burlesca, alegre e pitoresca, a segunda é séria e solene e a terceira é monumental, místico, fantástica e heróica. Cada uma delas se correspondendo com as cores: o amarelo, o rosa, e o negro. As cores em jogo são as primárias: vermelho, azul e amarelo. São associações às manifestações variadas de temperamentos humanos. O rosa é a intermediação entre as duas. O vermelho é a transição. O negro é a radicalização do caráter introspectivo do azul. Esta é a cor mais solene, metafísica. O amarelo se associa ao triângulo. O vermelho ao círculo e se associa ao homem. O quadrado ao azul. O quadrado é uma forma geométrica que gera o cubo e representa o espaço. São associações coerentes com o projeto pedagógico da Bauhaus.

Schlemmer desenvolveu a partir das relações entre o homem e o espaço do modernismo, um conjunto de teorias sobre a estruturação do homem como figura vertical que se movimenta dançando interativamente com o espaço e este o absorve em suas características. Tinha como objetivo a tipificação padronizada do corpo humano, definindo um caráter abstrato e geométrico das suas formas orientando-se para um construtivismo antropocêntrico, aplicado ao corpo através de meios plásticos elementares: a formulação da imagem do corpo dentro de um padrão universal.

Sua obra se inicia na pintura e no desenho como primeiros estágios, não para permanecer em uma estrutura bi-dimensional, mas que se realizará e se concluirá no espaço através da ação na dança, no teatro. O Ballet Triádico é uma dança para três: uma mulher e dois homens dançarinos. São doze danças e dezoito figurinos. Temos formas cúbicas, esféricas, piramidais e suas derivações seccionais, tanto na composição dos figurinos como na cenografia em que a figura humana é circunscrita em um universo marcado pela arquitetura com a matemática em evidência. Destacando o cubo, pelo ângulo reto e por ser este poliedro altamente simétrico ou seja, uma "arquitetura da carne". Ela reduz a organicidade natural e complexa do corpo humano a formas geométricas primitivas como a esfera, o cone, o cubo, os prismas de base retangular, o cilindro etc. Enfim busca nelas a regularidade necessária 
para desenvolver eficientes formas simplificadas que facilitam a mensuração da alta variabilidade, da ordem de milímetros, das formas do corpo ao longo de sua extensão.
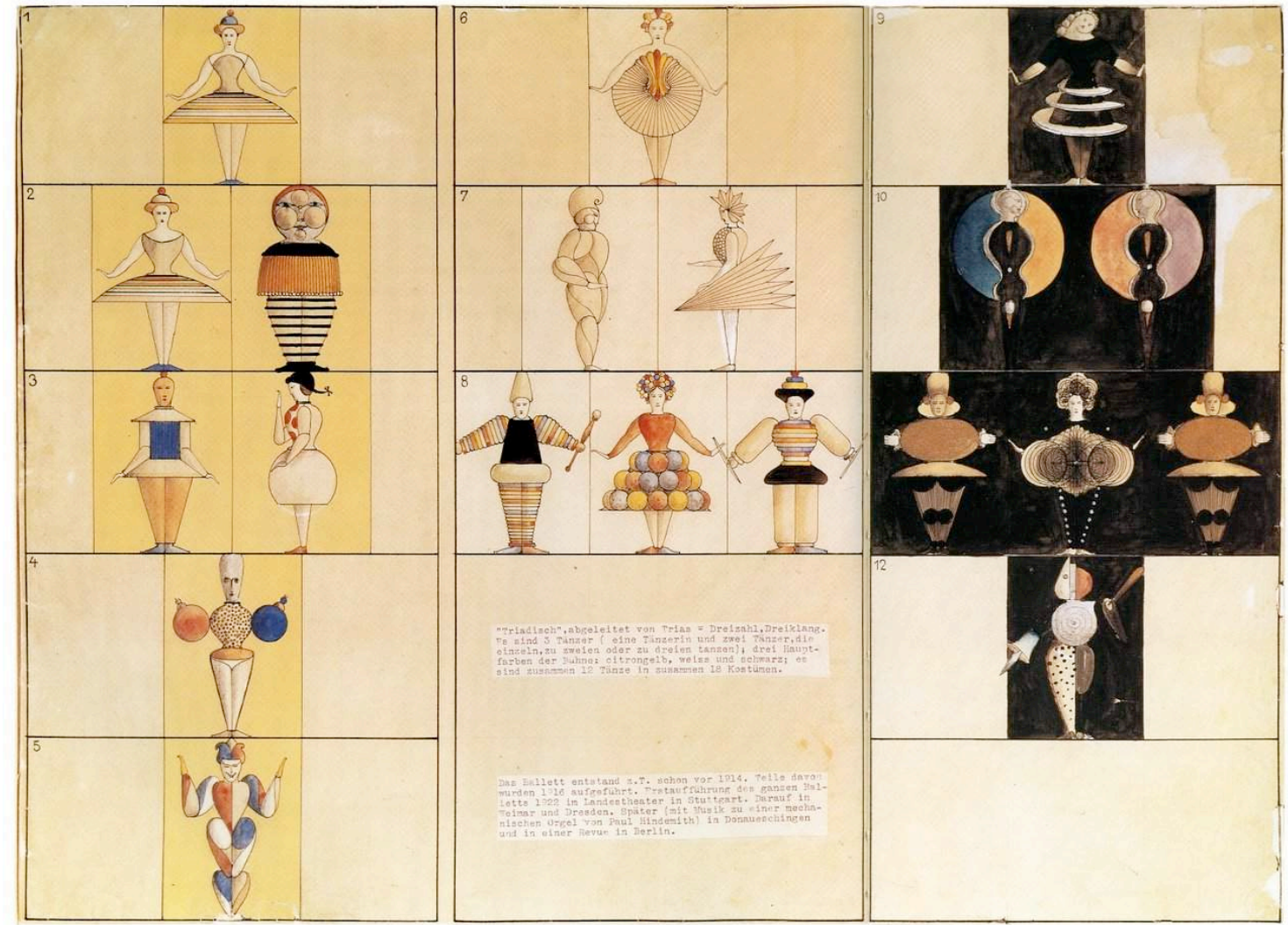

Figura 1 - Desenhos originais de Oskar Schlemmer para o figurino do Ballet Triadico. Disponível em <http://slcvisualresources.tumblr.com/image/25023343525> Acesso em 25/03/2014

Imaginárias linhas retas são traçadas tangentes a pontos proeminentes das inúmeras curvas deste, de modo a simplificá-las garantindo a construção de polígonos em planos de secção paralelos ao plano de apoio do corpo sobre o solo. A coluna torna-se um fio de prumo que se estende do topo do crânio à planta dos pés e que estrutura inúmeros planos paralelos perpendiculares a ele. Por estes planos é possível realizar a mensuração através de um corpo abstraído de sua irregularidade biomórfica. O processo construtivo em Schlemmer foi pensado através da transcodificação das formas orgânicas do corpo humano em volumes regulares da geometria plana e espacial seus figurinos partem de uma racionalidade mecanicista e lógica seu pensamento deduz um corpo de marionete.

O bailarino diante deste figurino encontrar-se-á diante de um segundo corpo que Ihe imporá a racionalidade das formas forjadas pela mente. Os movimentos já não podem ser livres e plasticamente vitais de acordo com a potencialidade natural e expressiva do bailarino. A sua vontade consciente tem de encontrar, nos limites da regularidade geométrica e de suas qualidades de abstração inerentes, saídas para movimentos acionados por sua energia vital, mas totalmente condicionados dentro de parâmetros rígidos e acrescidos do peso dos materiais como madeira e metal de que foram constituídos. 


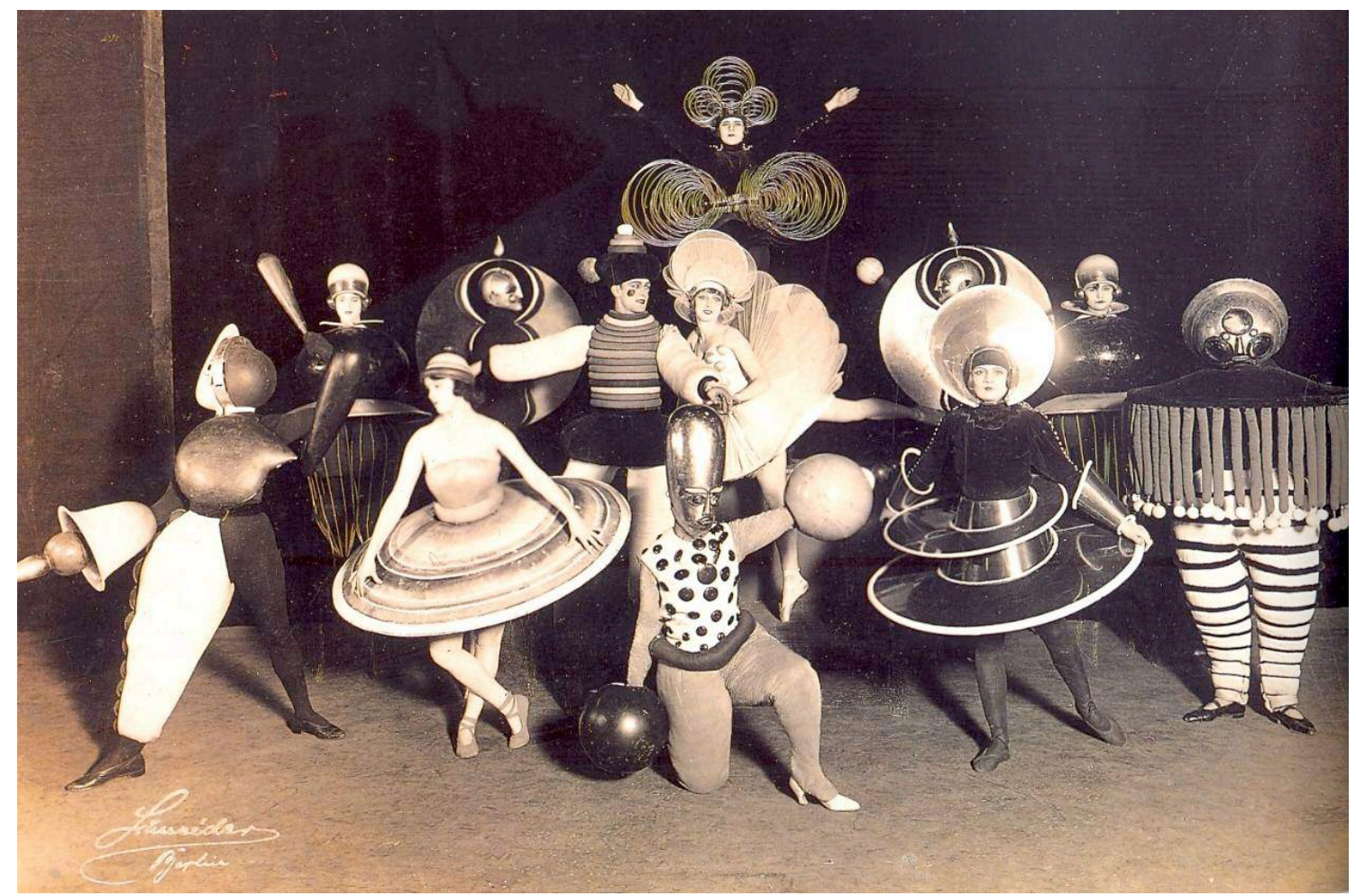

Figura 2 - 12 Figurinos do Balé Triádico de Oskar Schlemmer - Apresentação parcial no Teatro Metropol de Berlim, 1926. Disponível em < http://lounge.obviousmag.org/anna_anjos/2012/10/operamisturada-a-batidas-eletronicas.html>. Acesso em 20/03/2014

A coreografia teve como técnica a constrição de movimentos. O corpo foi metaforizado nas formas simples das marionetes e passaram a ser diagramas do corpo humano. Os figurinos têm peso, pelas dimensões e pelo material e são intencionalmente dificultadores do movimento. Esta interdição faz o bailarino repensar seu próprio estar no espaço e no tempo. É a procura da reestruturação da própria percepção do corpo, através de uma volta às limitações primárias.O corpo torna-se um Organismo Técnico com os seguintes movimentos: rotação, direção $e$ intersecção no espaço. O abstrato e o figurativo confundem-se. É uma síntese geométrica do real: o metaphysicum abstractum. Os dançarinos são transformados pelo figurino e movendo-se no espaço apresentam o caráter simbólico do ser humano como Figura da Arte. Isto é visível no homem quadriculado de seu curso "MAN" desenvolvido na Bauhaus. Schlemmer reafirma isto: "primeiro vem o figurino, depois a música que melhor se adapte a ele e finalmente a coreografia" (SCHLEMMER; 1971). Os figurinos são os fundamentos de toda a idéia coreográfica. É mais profundo, estrutural e integrador dentro de uma perspectiva wagneriana de Arte Total. Há como resultado uma unidade estética entre a cenografia, a coreografia, a música e os figurinos. No Ballet Triádico, temos uma hierarquia liderada pelo figurino, mas que conceitualmente é preparada pela estereometria do espaço, ou seja, de como o movimento do corpo no espaço molda dinamicamente a volumetria imediatamente circunscrita a ele rompendo a clássica plástica da dualidade figura-fundo. No período entre duas guerras em que os figurinos foram executados pela primeira vez, não havia grande possibilidades de materiais disponíveis na Bauhaus. As duas grandes oficinas de madeira e metal é que ofereceram criativamente alguns recursos como, por exemplo, uma saia rodada de madeira, secção de uma esfera, da primeira bailarina da primeira 
parte amarela. Algumas máscaras de couro brilhante ou metal, esferas pintadas de listras coloridas com tinta metálica, feitas em madeira enfiadas através de cavidades cilíndricas nos braços. E também o uso do papel maché nas máscaras e em esferas para o tórax.

\section{O PERCURSO DA RECONSTITUIÇÃO}

O caráter experimental do ballet de Schlemmer logo se refletiu na natureza dos desafios que se impuseram. Sabíamos que o escopo do trabalho era extenso, o tempo limitado e soava como um mantra que se repete 'a exaustão, a lembrança de que sua finalidade era essencialmente a produção de conhecimento. Isto significava que era imperativo que houvesse uma coordenação precisa entre as especialidades do design envolvidas, que se compusesse uma equipe motivada pelo espírito de cooperação e objetividade, e que se mantivesse sempre `a vista sua motivação educacional. Assim, do grupo chamado originalmente 'prático' (que compunha com o grupo 'teórico'), foram criados dois sub-grupos segundo suas competências e especialidades técnicas:

2.1 O primeiro sub-grupo ligado ao curso de moda responsabilizou-se pelas modelagens em tecido. Foram utilizados corpos duplos de base com enchimento de manta acrílica revestidas por espuma e sobrepostas por um macacão de malha viscolycra, nas cores preta e branca. Os conjuntos todos foram finalmente recobertos pela última camada que apresenta a caracterização do figurino, com neoprene, em diversas cores.

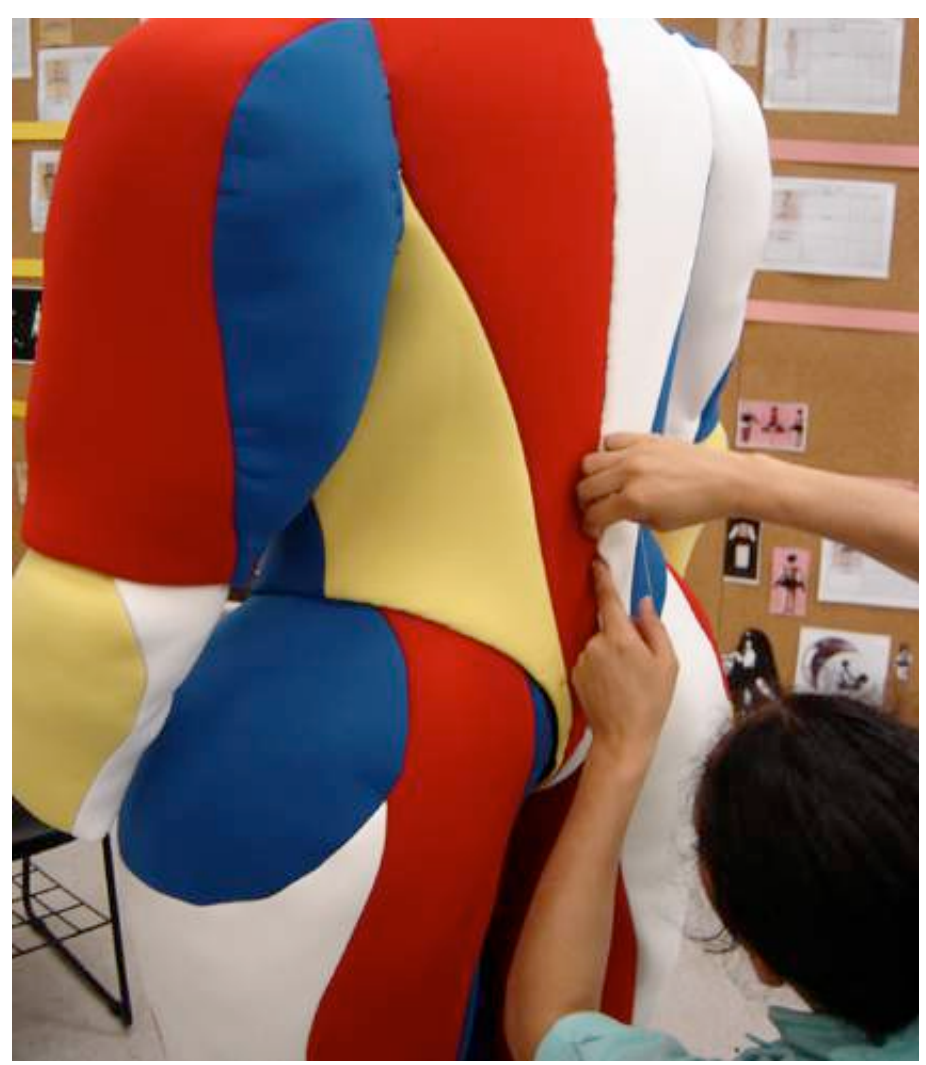

Figura 3 - Equipe de modelagem em tecido Neoprene, ajusta o primeiro figurino reconstituído, Arlequim. "Imagem elaborada pelos autores, com base nas pesquisas iniciais realizada no "Laboratório de Criação". Autor da foto: Ernesto G. Boccara. 
2.2. Ao segundo sub-grupo coube a modelagem das partes rígidas dos figurinos, e envolveu, entre alunos, professores e técnicos, uma equipe que teve como centro de operações uma oficina de Design Industrial, estruturada para a construção de modelos e protótipos.

\section{O TRABALHO DO SEGUNDO SUB-GRUPO: MODELAGEM DAS PARTES RÍGIDAS}

O trabalho na oficina de design industrial viveu duas fases equivalentes em tempo e volume de produção: A primeira, sob a coordenação compartilhada de dois discentes do programa de pós-graduação do Instituto de Artes da UNICAMP convidados a participar do projeto, Fernando da Silva Ramos e Thiago José Cóser, e a segunda coordenada pelo professor Gilberto Vançan, do curso de artes visuais do SENAC.

$\mathrm{Na}$ primeira fase, os dilemas conformaram-se em relação `a natureza dos materiais e processos de modelagem. Por tratar-se de uma reconstituição, um dos questionamentos da equipe foi se valeria a pena o empenho de incorporar os materiais e técnicas usados na produção dos figurinos originais; o dilema durou pouco, e esta idéia não vingou por diversas razões.

A primeira ressalva considerou que ‘a época em que foram modelados os figurinos originais, no início da década de 20 do século passado, a Alemanha vinha de um período de guerra e conseqüente escassez de recursos, e sendo assim, muitos dos processos e técnicas que Schlemmer e seu grupo de estudantes utilizaram resultaram daquilo que encontraram `a disposição, e que diante das condições, foram obrigados a adaptar. Uma segunda ressalva a esta abordagem, lembrava que o material de pesquisa levantado pelo 'grupo téorico' - por falta de registro disponível, não informava com precisão os processos que foram empregados. Uma terceira consideração disse respeito 'a capacitação da equipe no manejo de técnicas que há muito não se usa em escolas de Design, como a modelagem de chapas metálicas com martelo e bigorna, por exemplo; será que valeria a pena investir tempo e energia em aprendermos uma técnica tão específica para reconstituirmos os figurinos não só sob o aspecto formal, mas também os segundo o emprego dos materiais?

A solução adotada frente a esses dilemas foi considerar o espírito pragmático de Schlemmer e não cristalizar os procedimentos, mas ao contrario, poderíamos adotar sua capacidade de improviso e adaptabilidade 'as condições, como um aspecto a ser incorporado como princípio, também na reconstituição.

Pela diversidade formal informada pelos desenhos de Schlemmer, tornou-se claro que uma única técnica de modelagem não seria suficiente para resolver toda a demanda. Levantou-se diversas hipóteses sobre a adoção de materiais e processos, mas não havia consenso sobre os caminhos a seguir.

Assim, resolveu-se dedicar algum tempo e recursos para configurar uma estratégia prática e comprometer a equipe. O planejamento considerou o princípio pedagógico de que um método é mais eficaz quando é ensinado na progressão de um problema do mundo real, no qual um problema real é apresentado aos alunos, lhes são oferecidos os meios, e pedido para que construam suas próprias soluções. 
Desta maneira, estabeleceu-se dois momentos para o trabalho na oficina de design industrial: O primeiro, de caráter preliminar, na forma de um 'exercício de treinamento', e o segundo, na 'produção dos figurinos' propriamente ditos.

O chamado 'exercício de treinamento' consistiu na modelagem de uma 'forma tipo' sobre a qual a equipe poderia praticar experimentando diversos materiais e técnicas, com o propósito de identificar diferenças e semelhanças, bem como suas vantagens e desvantagens relativas. A expectativa era de que a partir deste aquecimento, a equipe fosse capaz de descrever e replicar as aquisições da experiência na modelagem dos figurinos, com o máximo de autonomia individual e espírito de colaboração.

A opção por um exercício introdutório mostrou-se adequada, pois ao uniformizar o conhecimento, observou-se mais tarde uma participação mais ativa da equipe como um todo desde o início, inclusive em demandas ligadas ao planejamento, como na organização das listas de materiais e dos cronogramas.

\subsection{Exercícios preliminares: Os primeiros passos do planejamento}

Os primeiros esforços trataram de investigar a plasticidade e comportamento de alguns dos materiais mais comuns na execução de protótipos industriais: Gesso, arame, estopa, madeira, resinas, fibra de vidro, borracha de silicone, espuma de poliuretano, papelão, colas e pigmentos.

A 'forma tipo' foi construída simultaneamente em quatro versões a partir da associação dos diversos materiais. Uma mesma estrutura radial de mdf cortado a laser no LAPAC 1 , garantiu os mesmos parâmetros iniciais de forma e escala ’as quatro modelagens.
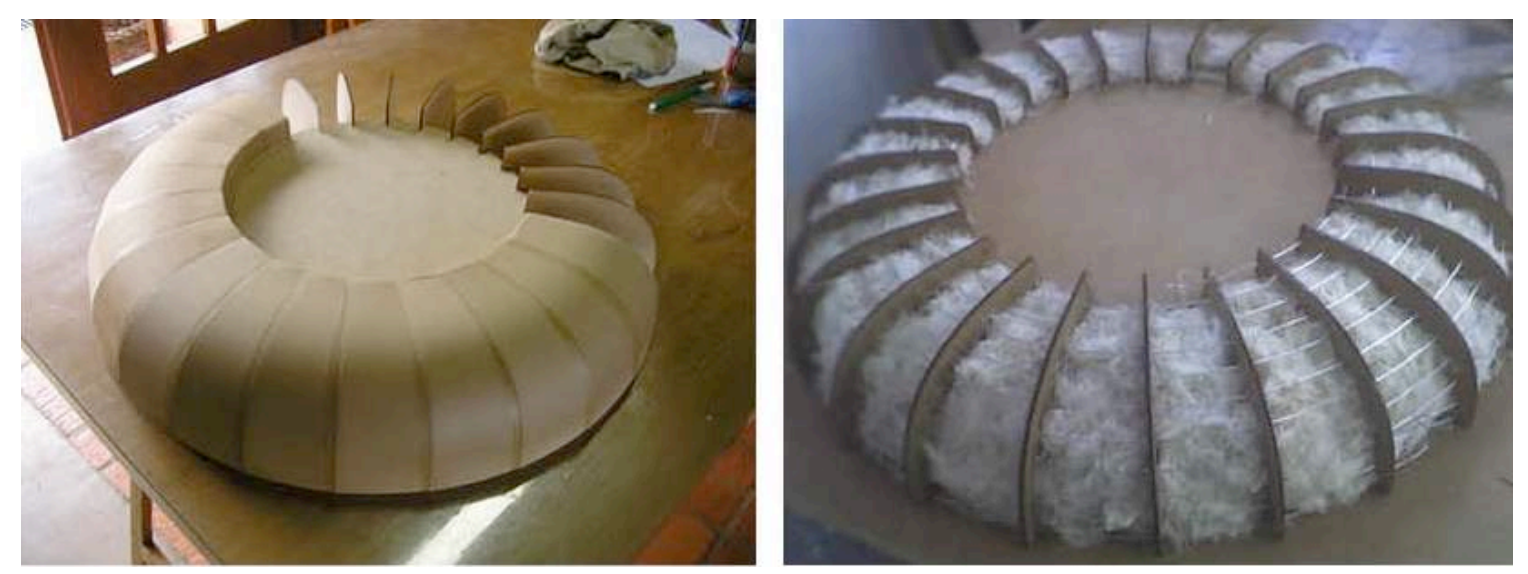

Figura 4 - Versão no 1 da 'forma tipo' ‘a esquerda: espaços entre as lâminas de mdf foram preenchidos por tiras coladas de papel craft. Versão no 2 `a direita: Vãos entre as láminas preenchidas por arame, estopa e gesso - "Imagens elaboradas pelos autores, com base na pesquisa realizada"

\footnotetext{
${ }^{1}$ http://lapac.fec.unicamp.br
} 

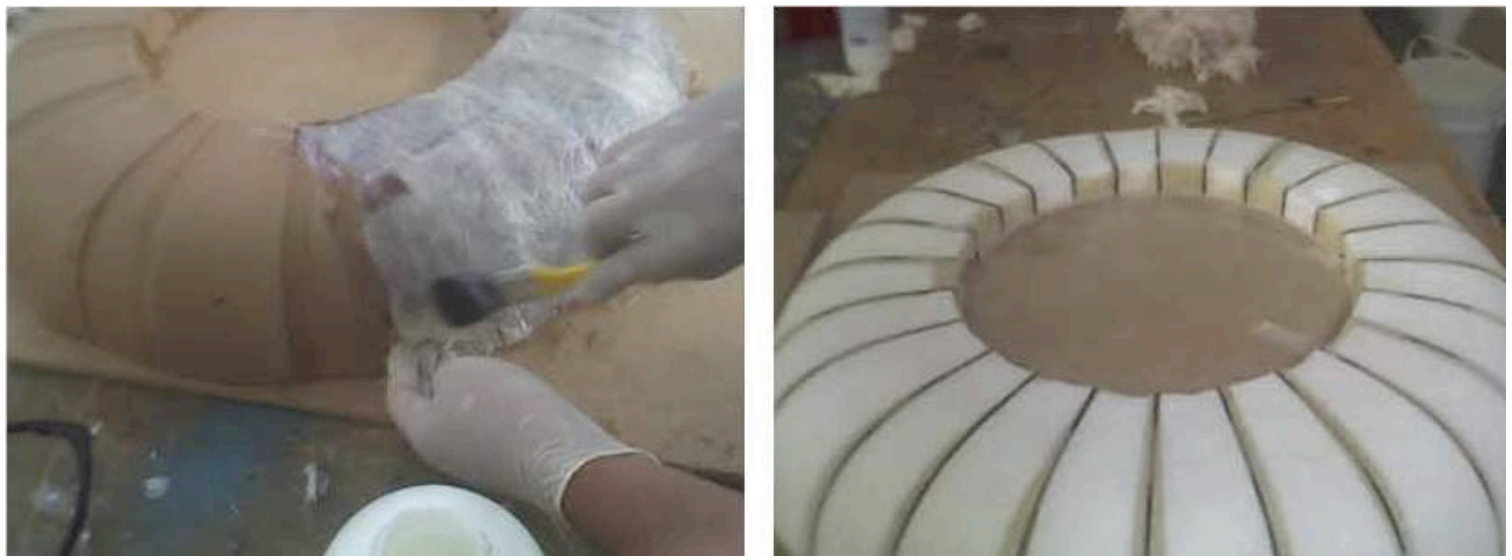

Figura 5 - Versão no 3 da 'forma tipo' ‘a equerda: utilização de tiras de papelão couro revestido por fibra de vidro. Na versão no 4, ’a direita, utilizou-se isopor de alta densidade e poliuretano expandido entre as lâminas de $\boldsymbol{m d f}$ - "Imagens elaboradas pelos autores, com base na pesquisa realizada"

A avaliação dos resultados deste exercício preliminar foi importante `a sequência do trabalho. Diversas estratégias que se supunha serem boas soluções foram reavaliadas em vista de alternativas que surgiram ao longo da prática. $O$ fato é que pouco se usou o papelão e o gesso, a não ser como material de apoio de importância secundária. O papelão por exemplo, era o material base para uma maneira de se prototipar a partir de modelagens digitais e planificação. Verificou-se que esse procedimento poderia alcançar bons resultados para peças com a geometria facetada, pois os planos poderiam juntar-se com os vincos naturais sem nenhum problema. No entanto, para peças orgânicas os vincos foram um problema para o qual não se viu solução, e por isso, esse processo não foi adotado neste trabalho.

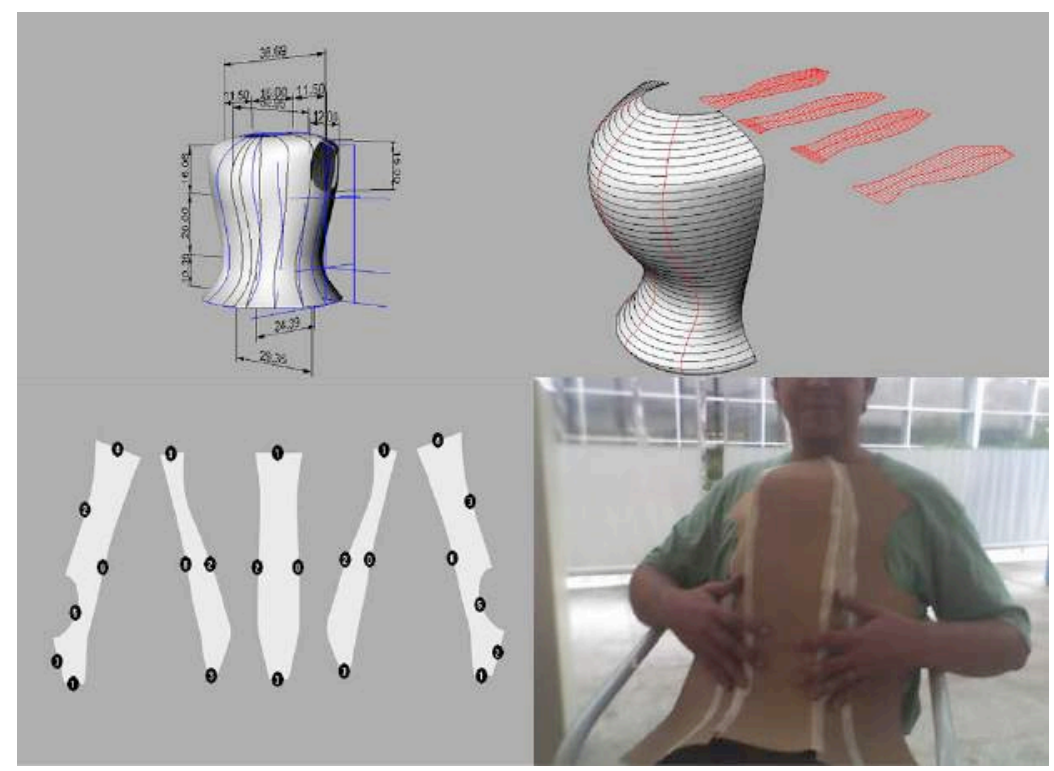

Figura 6 - Experiência em papelão material base para prototipagem a partir de modelagens digitais e planificação. - "Imagens elaboradas pelos autores, com base na pesquisa realizada"

O processo que envolve a fibra de vidro por exemplo, que embora seja muito conhecido e acessível, nunca havia sido empregado por nenhum dos integrantes da equipe, na escala e dimensões dos figurinos. Neste caso, como ficou evidente que seu 
emprego poderia ser uma boa resposta 'as peças que demandavam serem leves e resistentes, foi necessário um período de capacitação de parte da equipe em uma fábrica de artefatos de fibra de vidro, para garantir a qualidade do resultado final.

$\mathrm{O}$ isopor de alta densidade também foi preferido quando confrontado com uma outra opção possível, o poliuretano. Além do custo consideravelmente mais baixo de seu metro cúbico, o isopor quando lixado produz uma poeira que não irrita a pele, ao contrario do poliuretano. No entanto, a resina de poliéster, que faz parte do compósito fibra de vidro, é altamente corrosiva ao isopor, e isso demandou a procura por soluções para a impermeabilização das peças, para que a modelagem não fosse derretida pelos solventes no momento da execução dos moldes. Utilizou-se a massa corrida diretamente sobre $\mathrm{o}$ isopor, com acabamento em tinta esmalte 'a base de água.

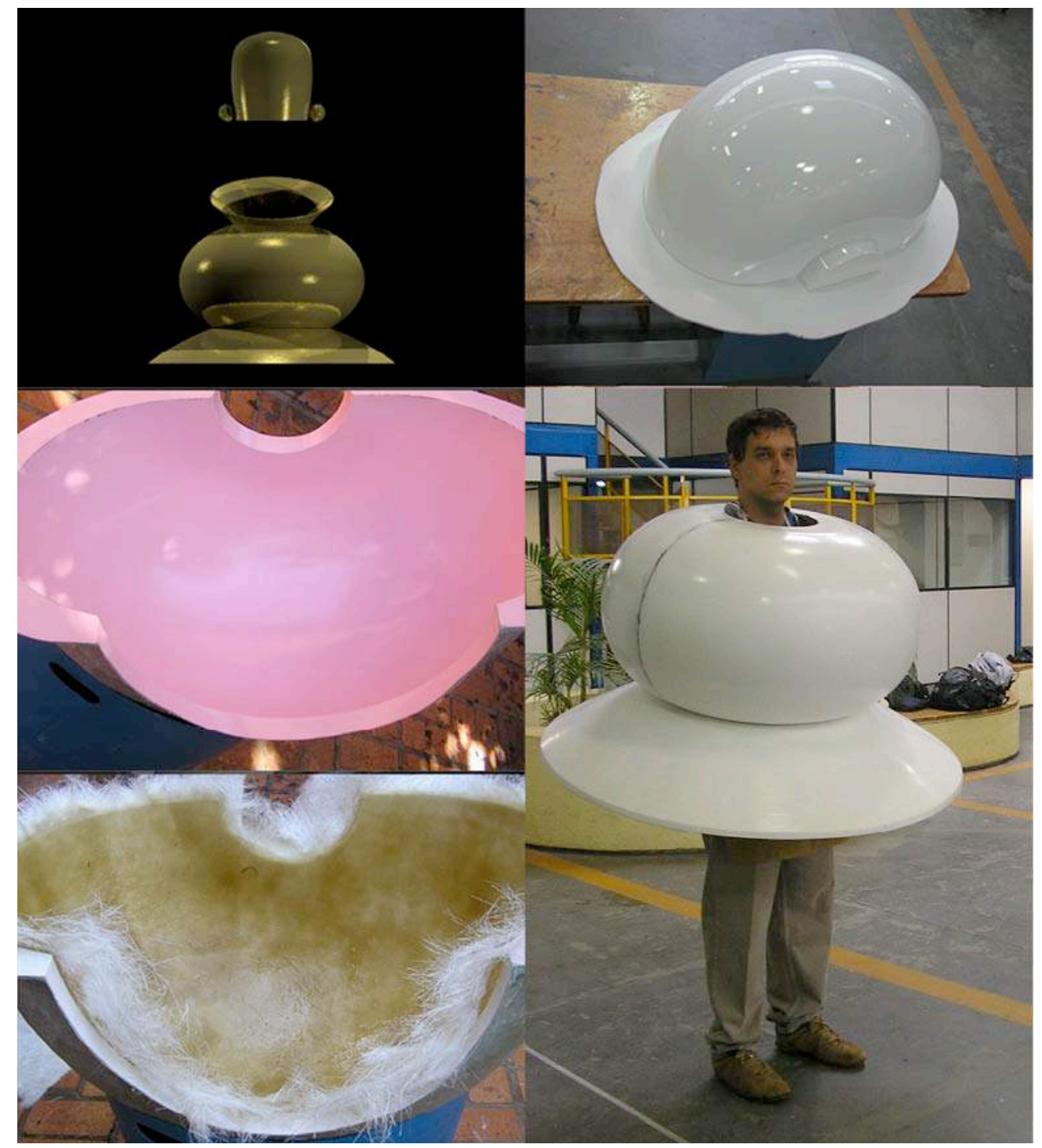

Figura 7 - Etapas do processo de modelagem do figurino Bola de Ouro: Projeto digital / modelagem em isopor e preparação para o molde / molde e peça em fibra de vidro / teste da peça pré-pintura. "Imagens elaboradas pelos autores, com base na pesquisa realizada". 
Em praticamente todas as modelagens que envolveram partes duras, houve um prévio projeto feito através do computador. No caso da peça ilustrada na figura 8 , a cabeça do mergulhador, os parâmetros de proporções vieram dos desenhos de época de Schlemmer. A exemplo dos processos experimentados no exercício preliminar, a gola foi modelada a partir de uma estrutura em cavernas de $m d f$ e preenchida com placas de poliuretano, e inteiramente executada por alunos do Design Industrial.

Uma vez laminadas em fibra de vidro, a partir de moldes também de fibra de vidro, as peças receberam acabamento em tinta automotiva.

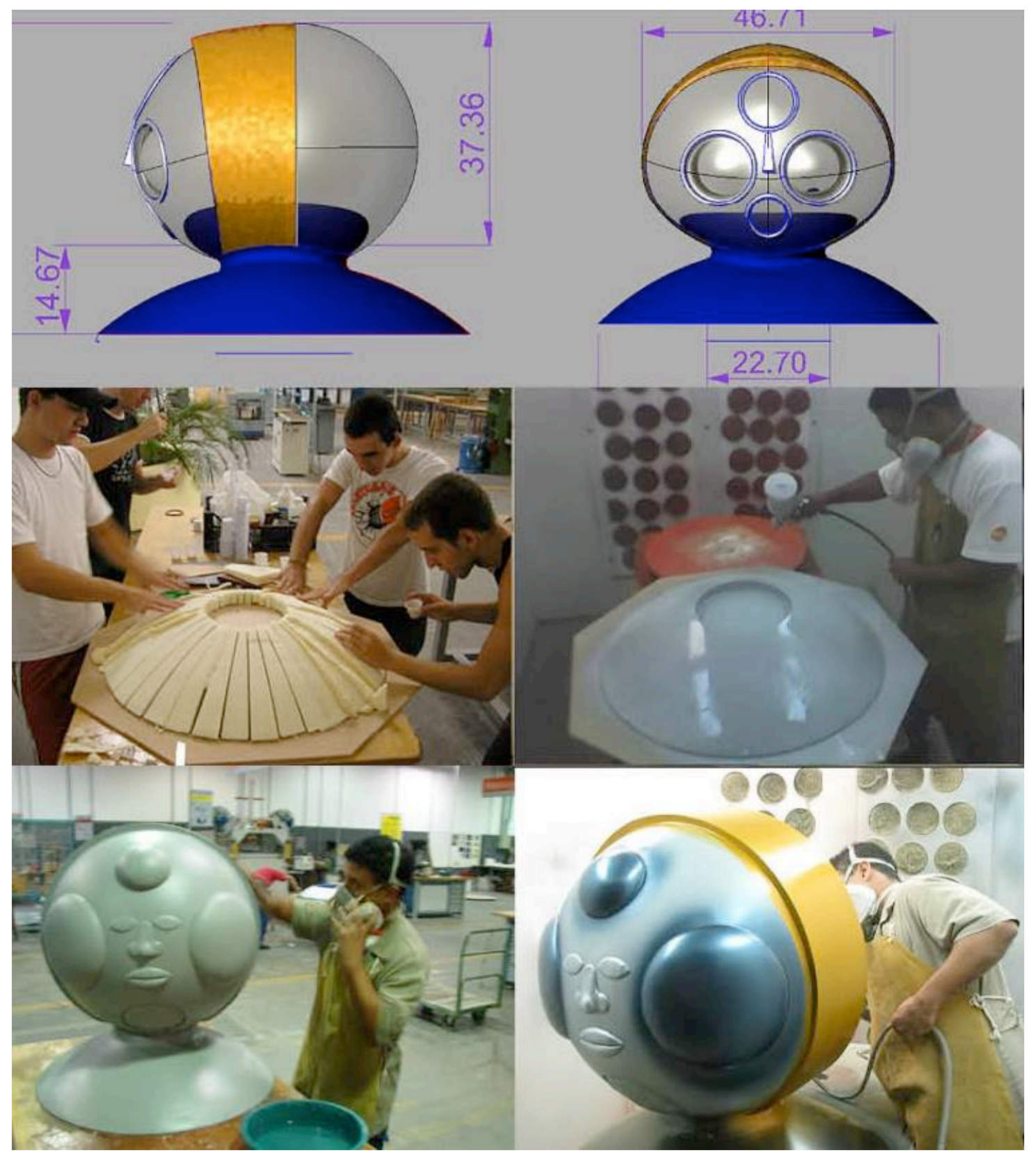

Figura 8 - Cabeça do figurino 0 Mergulhador. Fase Amarela. Alunos do Curso de Design durante o processo de Execução na Oficina de Design - "Imagens elaboradas pelos autores, com base na pesquisa realizada" 


\section{OS RESULTADOS DA PESQUISA}

A meta principal orientadora desta pesquisa foi a produção dos Figurinos, para que fossem usados em ação para a dança e para serem expostos. A pesquisa ao longo de seu desenvolvimento gerou e continuará a gerar material informativo de real valor no plano do ensino da graduação em moda, design, artes plásticas e cênica, dança, teatro, cinema e televisão. Com relatos da experiência, descrições, documentação da produção de conhecimento, a pesquisa tem sido divulgada em Encontros de pesquisa e extensão, seminários de pesquisa, colóquios, congressos, palestras em várias universidades, publicações eletrônicas e impressas, publicações em capítulos de livro e em importantes apresentações públicas em palco e exposições paralelas. Destaca-se que, após a primeira fase entre 2007 a 2009, quando já se tinha executado onze do total de dezoito figurinos, eles estrearam publicamente e foram exibidos em exposição e através de dança no palco do Centro de Convenções do C. U. SENAC no campus Santo Amaro em 10 de outubro de 2008, penúltimo dia do evento internacional do 8으 P\&D Design, que reuniu mais de 600 pessoas em seu auditório central.

A conclusão do projeto ocorreu em 30 de maio de 2010 com os 18 figurinos em cena. Para a exibição foi produzido um documentário com depoimentos dos principais participantes, expondo os conceitos e o processo de reconstituição histórico destacando o fato de que ter todos o figurinos em cena e dançáveis é uma raridade no contexto do conjunto das poucas reconstituições completas no mundo. Após a apresentação foi realizado um registro em video-clip, da dança, da coreografia ,dos figurinos e da re-leitura de uma das composições originais para o Ballet original. Os dois vídeos estão publicados no Youtube ${ }^{2}$ desde 2010 com centenas de fotos da documentação do processo passo a passo.

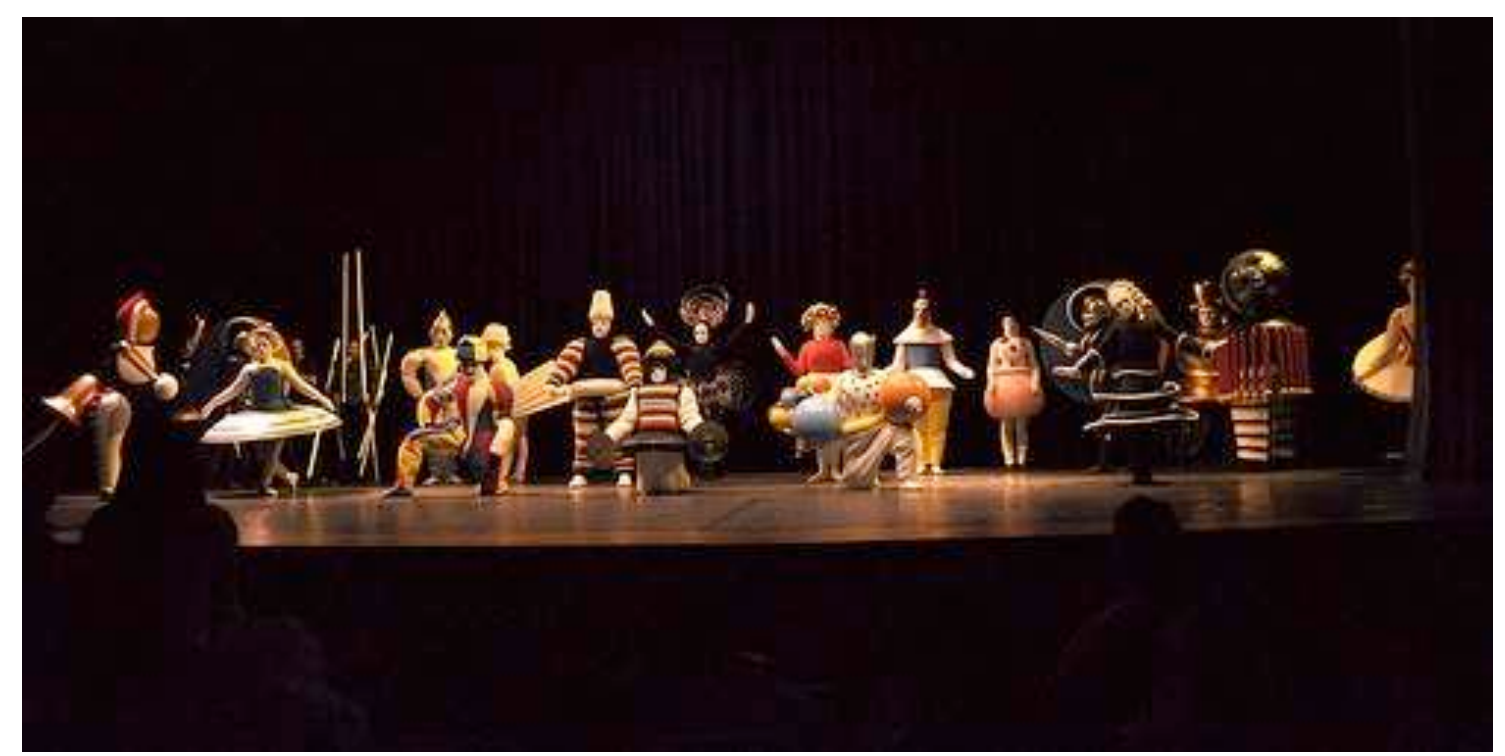

Figura 9 - Conclusão da Pesquisa: em cena os 18 figurinos, em 30 de Abril de 2010. Palco do Centro de Convenções do C. U. SENAC - Disponível em http://projetofigurino.tumblr.com/post/613711304/elenco> Acesso em 25/03/2014

\footnotetext{
${ }^{2}$ https://www.youtube.com/watch?v=gStZdni5bTs
} 
Em Junho de 2013 na Biblioteca do C. U. SENAC ocorreu uma Exposição dos figurinos reconstituídos na Biblioteca, realizada em parceria com o Instituto Goethe de São Paulo que contou com a presença de dois pesquisadores da Fundação da Bauhaus (Dessau-Alemanha). Neste contato os pesquisadores da Bauhaus reafirmaram a qualidade desta reconstituição brasileira, uma das poucas e completa no mundo com 18 figurinos vestíveis e dançáveis. Eles receberam estes figurinos em doação para serem exibidos a partir de 2014 e principalmente durante o ano de 2019, ano do centenário da Bauhaus, na Fundação Bauhaus em Dessau-Alemanha.

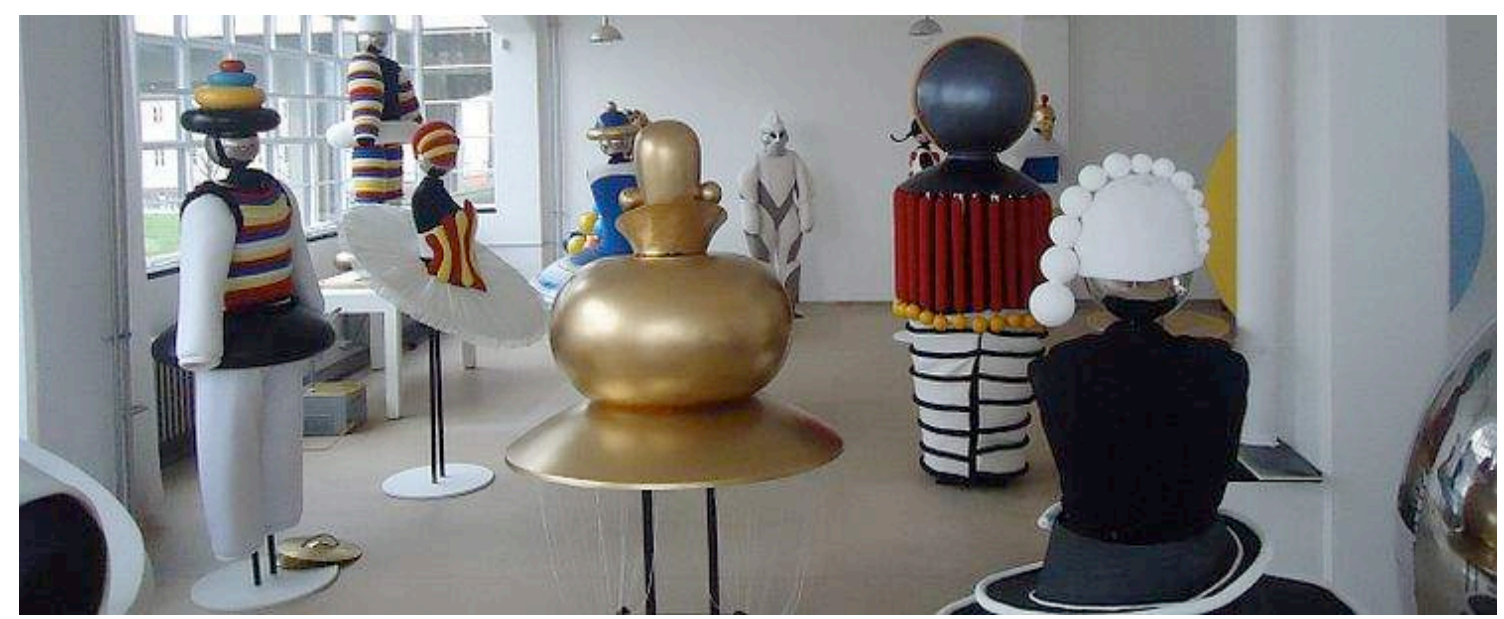

Figura 10 - Os 18 Figurinos da Reconstituição Brasileira expostos na Fundação Bauhaus em Dessau, Alemanha. Disponível em:

<https://www.sp.senac.br/jsp/default.jsp?tab=00002\&newsID=a21541.htm\&subTab=00000\&uf=\&loc al=\&testeira=722\&I=\&template=1100.dwt\&template2=\&unit=\&print=T> Acesso em 25/03/2014

\section{REFERÊNCIAS BIBLIOGRÁFICAS:}

AGRA, Lucio. História da Arte do Século XX. São Paulo: Editora Anhembi Morumbi, 2004.

Construtivismo na Arte e Projeto Intersemiótico, PUC-SP, Mestrado em Comunicação e Semiótica, 2003.

BOCCARA,Ernesto G. Figuras de Arte : A reconstiuição dos Figurinos do Ballet triádico.Relato de Uma experiência Brasileira, Diário de Pesquisadores:Traje de Cena.Editora Estação das Letras e Cores.São Paulo.2012 GOLDBERG, Rose Lee. A Arte da Performance. São Paulo: Martins Fontes, 2006.

DROSTE, Madelene. Bauhaus archiv 1919-1933. Berlim: Benedict Taschen, 1999.

SCHLEMMER, Oskar. Escritos sobre Arte: Pintura, Teatro, Ballet. Cartas y Diários. Barcelona, 1977.

. Man. Londres: A Bauhaus Book, Lund Humphries, 1971.

LIMA, Evelyn Furquim Werneck. Concepções espaciais: 0 teatro e a Bauhaus. Disponível em: <http://www.unirio.brq/opercevejoonline/7/artigos3.htm. > Acesso em: 20 abril 2007. 